\title{
FUTURE EXPANSION OF THE LIGHTNING SURVEILLANCE SYSTEM AT THE KENNEDY SPACE CENTER AND THE CAPE CANAVERAL AIR FORCE STATION, FLORIDA, USA
}

\author{
C.T. Mata, J.G. Wilson \\ ESC, KSC NASA, KSC \\ Carlos.T.Mata@nasa.gov Jennifer.G.Wilson $@$ nasa.gov
}

\begin{abstract}
The NASA Kennedy Space Center (KSC) and the Air Force Eastern Range (ER) use data from two cloud-to-ground (CG) lightning detection networks, the Cloud-to-Ground Lightning Surveillance System (CGLSS) and the U.S. National Lightning Detection Network (NLDN), and a volumetric mapping array, the lightning detection and ranging II (LDAR II) system. These systems are used to monitor and characterize lightning that is potentially hazardous to launch or ground operations and hardware. These systems are not perfect and both have documented missed lightning events when compared to the existing lightning surveillance system at Launch Complex 39B (LC39B). Because of this finding it is NASA's plan to install a lightning surveillance system around each of the active launch pads sharing site locations and triggering capabilities when possible. This paper shows how the existing lightning surveillance system at LC39B has performed in 2011 as well as the plan for the expansion around all active pads.
\end{abstract}

\section{INTRODUCTION}

The CGLSS contains six medium-gain IMPACT ESP sensors placed $\sim 30 \mathrm{~km}$ apart. The CGLSS data are processed in the following sequence: 1) two or more remote sensors detect an electromagnetic waveform that is characteristic of a return stroke in CG lightning; 2) the GPS time, and the stroke amplitude, polarity, and magnetic direction are transmitted via land-line communications to a central processor; 3) the central processor uses timecoincident data from two or more sensors to compute an optimum stroke location and an estimate of the peak current, Ip, that is based on the range-normalized signal amplitude; and 4) the lightning information is forwarded to users in real-time via terrestrial data links. Included in these data are the value of a normalized chi-square $\left(\chi^{2}\right)$ error function at the optimum location and the length and orientation of the semi-major axis (SMA) of a confidence ellipse that describes the accuracy of the location (Cummins et al., 1998). The value of $\chi 2$ is a normalized measure of the "agreement" among all reporting sensors. Ideally, the distribution of $\chi 2$ values has a mean and median of unity, but values between 0 and 3 are considered to be "good," and values between 3 and 10 are "acceptable." The semi-major and semi-minor axes of the confidence ellipse characterize the dimensions of a region that contains the actual stroke location (to within a given probability), and are based on a two-dimensional Gaussian distribution of location errors that are inferred from known measurement errors and the geometry of the sensor locations [see Cummins et al. (1998)]. The CGLSS uses a "One Standard Deviation" confidence region (i.e. $\mathrm{P}=0.39$ ), and this is associated with a location error of about $250 \mathrm{~m}$ for CGLSS (Ward et al., 2008). This can be converted to a $50 \%$ confidence region by multiplying the length of the SMA by a factor of 1.177 , which gives $294 \mathrm{~m}$.

The NLDN is a national network of 113 high-gain IMPACT ESP sensors that are placed 200-350 km apart. The NLDN data are processed in the following sequence: 1) two or more remote sensors detect an electromagnetic waveform that is characteristic of a return stroke in CG lightning; 2) the GPS time, and the stroke amplitude, polarity, and magnetic direction are transmitted via satellite communications to a network control center in Tucson, Arizona; 3) information derived from multiple sensors is used to geo-locate the event and estimate the peak current (and polarity) of each stroke; and 4) the lightning information is forwarded to users in real-time via either terrestrial or satellite data links. This entire process takes approximately 30-40 seconds (Cummins et al., 2006).

The LDAR system is a volumetric VHF lightning mapping array that contains 9 time-of-arrival (TOA) receivers processed through the same central processor. This system locates the sources of large radio impulses (centered at $66 \mathrm{MHz}$ with a $6 \mathrm{MHz}$ bandwidth) and has a median location accuracy of about $100 \mathrm{~m}$ within $3 \mathrm{~km}$ of the LDAR central site (Maier et al., 1995). The primary sources of lightning VHF radiation are thought to be the stepped-leaders and other processes associated with the electrical breakdown of virgin air. The LDAR data consisted of the GPS date and time, together with the latitude, longitude, and altitude (in meters), of each VHF pulse that was located by the LDAR system during the flash. When fully operational, the LDAR flash detection efficiency is close to $100 \%$, and the false alarm rate is less than 1\% (Maier et al., 1995). For more details about the LDAR system and its performance see Lennon and Maier (1991), Maier et al. (1995), and Boccippio et al. (2000a,b). 


\section{IMPACT SENSOR WEAKNESSES}

Because of known differences in the network geometries and sensor gains, a comparison study was completed in 2007 comparing the NLDN and CGLSS networks. As expected the results yield that the NLDN does not report $17.5 \%$ of the negative first strokes (and strokes in new channels) that have a low Ip ( $2 \mathrm{kA}<|\mathrm{Ip}|<12 \mathrm{kA})$, or $2 \%$ of total events; both networks report $95 \%$ of the negative strokes that have intermediate values of Ip $(12<|\operatorname{Ip}|<50 \mathrm{kA})$; and the CGLSS fails to report $28 \%$ of the high-current events ( $|\mathrm{Ip}| \geq 50 \mathrm{kA})$, or $2.8 \%$ of total events. Furthermore, recent comparisons of NLDN and CGLSS networks reveal that these networks are missing about $13 \%$ and $30 \%$ of all strokes, respectively, when compared to ground-truth data from the new lightning instrumentation system installed at Launch Complex 39B at the Kennedy Space Center (Mata et al., 2012).

\section{FUTURE EXPANSION}

Data acquired by the Launch Complex 39B (LC39B) lightning instrumentation system has demonstrated a lower than expected CGLSS and NLDN detection efficiency (Mata et al., 2012), which has prompted the expansion of the LC39B lightning surveillance system to monitor other actives pads around KSC and CCAFS. Magnetic field stations and high speed video cameras will be added to monitor the Atlas and Delta launch pads, allowing the synchronization of all lightning surveillance systems at all launch pads to increase the stroke detection efficiency to $100 \%$ at the active launch pads.

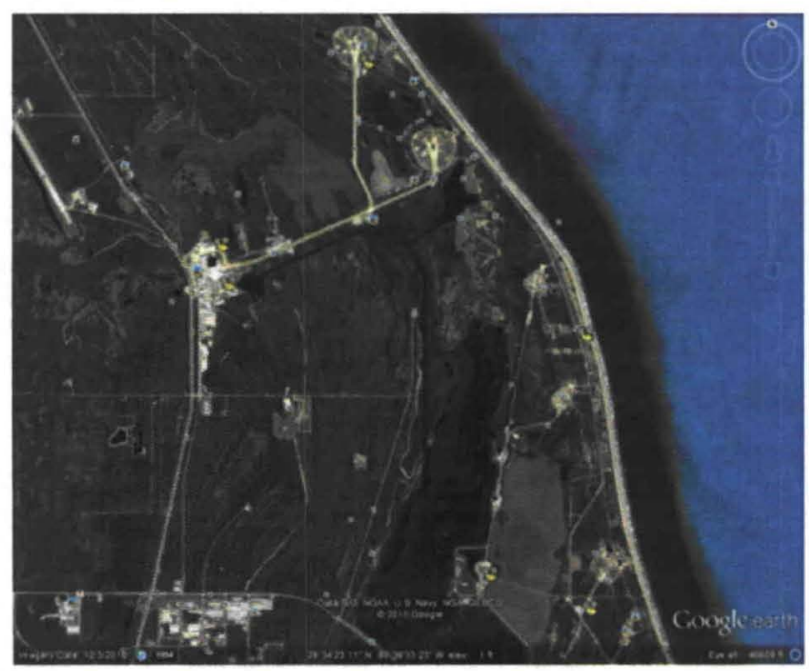

Figure 1. Total KSC/CCAFS launch pad lightning surveillance
The future expansion will use $\mathrm{dH} / \mathrm{dt}$ stations, similar to those used in the LC39B lightning instrumentation system, to monitor for lightning activity, characterize the lightning strikes, and trigger the high speed cameras to capture the events and determine their location. These will be 24/7 systems that will allow for the improvements of systems such as CGLSS and NLDN providing ground-truth data and necessary information to increase the detection efficiency of such systems.

The LC39B lightning instrumentation system is described in detail in Mata et al., 2010. In summary, the instrumentation system uses high speed, fiber optic isolated digitizers, installed on the field as close as possible to the $\mathrm{dH} / \mathrm{dt}$ sensors, that connect to a transient recorder at a central location. The transient recorder configures the dynamic range of the digitizers through a computer that controls the transient recorder. Qualified triggers are setup in the transient recorder, which time-stamp the qualified trigger events. A segmented, circular butter allows for pretrigger and post-trigger information to be saved. The transient recorder has a FIFO that stores the data after a qualified trigger is observed and immediately starts transferring the data to the controlling computer. This architecture allows for no dead time between events resulting on a detection efficiency of $100 \%$.

The output trigger of the transient recorder is buffered and conditioned before it is sent to the high speed cameras via fiber optic cables. The high speed camera's memory is also segmented, but due to some housekeeping required after each event is captured, the high speed cameras have a dead time that can be found empirically and it depends mainly on the sampling rate and the size of the memory segments. The possibility of a high speed camera missing an event is mitigated by the $\mathrm{dH} / \mathrm{dt}$ sensor stations, which can be used to locate the strikes.

The high speed camera and $\mathrm{dH} / \mathrm{dt}$ stations have a surge suppression and EMI filtering stage, before the power is isolated and passed through a battery bank that powers up the stations. These stations have been tested to EMI and at Camp Blanding, Florida, where they have been exposed to lightning like conditions to verify their immunity to nearby lightning strikes. Although the stations installed at LC39B are relatively large in size, newer products are being considered and will be evaluated to make the stations lighter, easier to install, and more affordable.

\section{REFERENCES}

Boccippio, D.J., S. Heckman, and S. J. Goodman, 2000a: A diagnostic analysis of the Kennedy Space Center LDAR network 1. Data characteristics. J. Geophys. Res., 106, 4769-4786.

Boccippio D.J., S. Heckman, and S. J. Goodman, 2000b: A diagnostic analysis of the Kennedy Space Center LDAR 
network 2. Cross-sensor studies. J. Geophys. Res., 106, 4787-4796.

Cummins, K. L., J. A. Cramer, C. J. Biagi, E. P. Krider, J. Jerauld, M. A. Uman, and V.A. Rakov, 2006: The U.S. National Lightning Detection Network: Post-upgrade status, 2nd AMS Conference on Meteorological Applications of Lightning Data, Atlanta, GA, 29 January -2 February.

Cummins, K.L., M.J. Murphy, E.A. Bardo, W.L. Hiscox, R.B. Pyle, and A.E. Pifer, 1998: A combined TOA/MDF technology upgrade of the U.S. National Lightning Detection. Network, J. Geophys. Res., 98, 9035-9044.

Lennon, C. and L. Maier, 1991: Lightning Mapping System, Proc. International Aerospace and Ground Conference on Lightning and Static Electricity (ICOLSE), Vol. II, Cocoa Beach, FL, 16-19 April.

Maier, L., C. Lennon, T. Britt, and S. Schaefer, 1995 : Lightning Detection and Ranging (LDAR) System Performance Analysis. $6^{\text {th }}$ Conference on Aviation Weather Systems, Dallas, TX.

C. T. Mata, V. A Rakov, T. Bonilla, A. G. Mata, E. Navedo and G. P. Snyder, "A new comprehensive lightning instrumentation system for PAD 39B at the Kennedy Space Center, Florida" International Conference on Lightning Protection 2010, Cagliari, Italy, September 2010.

Mata, C.T., A.G. Mata, V.A. Rakov, A. Nag, J. Saul, 2012: Evaluation of the performance characteristics of CGLSS II and U.S. NDLN using ground-truth data from Launch Complex 39B, Kennedy Space Center, FL. International Lightning Detection Conference (ILDC), Broomfield, Colorado, 2-3 April 2012.

Ward, J. G., K. L. Cummins, E. P. Krider, 2008: Comparison of the KSC-ER Cloud-to-Ground Lightning Surveillance System (CGLSS) and the U.S. National Lightning Detection Network ${ }^{\mathrm{TM}}$ (NLDN), 20th International Lightning Detection Conference, 22-23 April 2008, 7 pp. 